\title{
Understanding the impact of second-hand smoke exposure on clinical outcomes in participants with COPD in the SPIROMICS cohort
}

\author{
Nirupama Putcha, ${ }^{1}$ R Graham Barr, ${ }^{2}$ Meilan K Han, ${ }^{3}$ Prescott G Woodruff, ${ }^{4}$ \\ Eugene R Bleecker, ${ }^{5}$ Richard E Kanner, ${ }^{6}$ Fernando J Martinez, ${ }^{7}$ Benjamin M Smith, ${ }^{2}$ \\ Donald P Tashkin, ${ }^{8}$ Russell P Bowler, ${ }^{9}$ Mark D Eisner, ${ }^{4,10}$ Stephen I Rennard, ${ }^{11}$ \\ Robert A Wise, ${ }^{1}$ Nadia N Hansel, ${ }^{1}$ for the SPIROMICS Investigators
}

\begin{abstract}
- Additional material is published online only. To view please visit the journal online (http://dx.doi.org/10.1136/ thoraxjnl-2015-207487).

For numbered affiliations see end of article.
\end{abstract}

\section{Correspondence to}

Dr Nirupama Putcha, 5501

Hopkins Bayview Circle, JHAAC 3B.22, Baltimore, MD 21224, USA; Nputcha1@jhmi.edu

Received 24 June 2015 Revised 1 February 2016 Accepted 3 February 2016 Published Online First 9 March 2016

\section{CrossMark}

To cite: Putcha N, Barr RG, Han MK, et al. Thorax 2016;71:411-420.

\section{ABSTRACT}

Background Second-hand smoke (SHS) exposure has been linked to the development of and morbidity from lung disease. We sought to advance understanding of the impact of SHS on health-related outcomes in individuals with COPD.

Methods Among the participants with COPD in SPIROMICS, recent SHS exposure was quantified as (1) hours of reported exposure in the past week or (2) reported living with a smoker. We performed adjusted regression for SHS with outcomes, testing for interactions with gender, race, smoking and obesity.

Results of the 1580 participants with COPD, 20\% reported living with a smoker and $27 \%$ reported exposure in the past week. Living with a smoker was associated with worse St George's Respiratory Questionnaire score (SGRQ, $\beta 3.10 ; 95 \% \mathrm{Cl} 0.99$ to 5.21), COPD Assessment Test score ( $\beta 1.43 ; 95 \% \mathrm{Cl} 0.52$ to 2.35$)$ and increased risk for severe exacerbations (OR 1.51, 95\% Cl 1.04 to 2.17). SHS exposure in the past week was associated with worse SGRQ ( $\beta 2.52 ; 95 \% \mathrm{Cl} 0.47$ to 4.58 ), nocturnal symptoms (OR 1.58; $95 \% \mathrm{Cl} 1.19$ to 2.10 ), wheezing (OR 1.34; $95 \% \mathrm{Cl} 1.02$ to 1.77), chronic productive cough (OR 1.77; 95\% Cl 1.33 to 2.35 ) and difficulty with cough and sputum (Ease of Cough and Sputum scale, $\beta 0.84 ; 95 \% \mathrm{Cl} 0.42$ to 1.25$)$. SHS was associated with increased airway wall thickness on CT but not emphysema. Active smokers, obese individuals and individuals with less severe airflow obstruction also had higher susceptibility to SHS for some outcomes.

Conclusion Individuals with COPD, including active smokers, have significant SHS exposure, associated with worse outcomes and airway wall thickness. Active smokers and obese individuals may have worse outcomes associated with SHS.

Trial registration number NCT01969344 (clinicaltrials.gov).

\section{INTRODUCTION}

Since the Surgeon General's report in 1964 linking tobacco smoke to lung cancer, the recognition of tobacco's impact on health has grown. ${ }^{1}$ There is increasing awareness of the role of second-hand smoke (SHS) exposure in contributing to adverse health outcomes, ${ }^{1}{ }^{2}$ including development of COPD. ${ }^{3-6}$ Moreover, the chemistry of SHS differs from that of primary smoke, creating the possibility

\section{Key message}

What is the key question?

- "Do individuals with COPD and exposure to secondhand smoke have worse outcomes compared to individuals with COPD not having exposure to secondhand smoke, and are there subgroups of COPD with higher susceptibility to such adverse outcomes?"

What is the bottom line?

- Individuals with COPD who are exposed to second-hand smoke have higher risk of worse outcomes including dyspnoea, lower exercise capacity and respiratory symptoms, and also have more airway wall thickness on CT.

\section{Why read on?}

- To the best of our knowledge, this is the first study that shows that second-hand smoke exposure is associated with adverse outcomes in current as well as former smokers with COPD, and the first to demonstrate distinct subgroups (current smokers, obese individuals, less severe airflow obstruction) that have a heightened susceptibility to adverse outcomes associated with second-hand smoke.

of SHS being an additional risk factor even for active smokers. ${ }^{7}$ Among those with COPD, a few studies suggest that SHS exposure adversely impacts quality of life, dyspnoea and risk of COPD exacerbation, but these studies are limited to former smokers. ${ }^{8-10}$ It is not fully known whether SHS is detrimental to health outcomes in COPD, and specifically it has not been shown whether SHS is detrimental in active smokers with COPD. Further highlighting the lack of evidence in this realm, the Global initiative for Obstructive Lung Disease (GOLD) consensus report, though noting the possible contribution of SHS to COPD incidence, does not mention SHS as a contributor to COPD morbidity. ${ }^{11}$ Additionally, whether there are subgroups of COPD at heightened susceptibility to SHS has not been elucidated, particularly in current smokers with heavy smoke exposure history. 
We sought to determine the independent contribution of SHS to clinical characteristics using validated exposure instruments, CT measures and validated COPD outcomes in a large study of former and current smokers with COPD having a high personal level of primary smoking history. We analysed the large, wellcharacterised COPD cohort in SPIROMICS ${ }^{12}$ in order to understand if important subgroups of individuals with COPD could be identified who might have heightened susceptibility to the negative impacts of SHS exposure, such as race and gender, given evidence in the literature of heightened susceptibility of African Americans and women ${ }^{13} 14$ to the effects of smoking, as well as obesity, given evidence of heightened susceptibility of obese individuals to indoor air pollution. ${ }^{15}$ Additionally, of interest was the potential heightened susceptibility of former smokers (compared with current active smokers) to the adverse effects of SHS.

\section{METHODS}

SPIROMICS $^{12}$ is a multicentre study of current and former smokers ( $\geq 20$ pack-years) with and without COPD and nonsmokers without COPD aged $40-80$ years. The original goals of the study were to determine intermediate outcomes and end points in the population with COPD in order to identify subgroups of individuals with COPD who could be targeted for future specific therapeutic strategies and treatments. Current and former smokers with (strata 3-4) and without COPD (stratum 2) were recruited, as were healthy, lifelong nonsmokers (stratum 1). We studied all individuals with COPD (post-bronchodilator $\mathrm{FEV}_{1} / \mathrm{FVC}$ of $<70 \%$ ) including subjects in strata $3\left(\mathrm{FEV}_{1} \geq 50 \%\right.$ predicted $)$ and $4\left(\mathrm{FEV}_{1}<50 \%\right.$ predicted $)$ in primary analysis. ${ }^{11}$ Secondary analyses incorporated individuals from strata 1-2. Further details on the study population can be found in the online supplementary material.

\section{SHS characterisation}

Participants were asked about smokers in the household. SHS exposure over the past week was quantified in hours using a validated questionnaire for the assessment of exposure in multiple locations including within and outside of the home (including other person's home, workplace, car or other location while travelling, place of entertainment and other location). ${ }^{9} \quad 16$ Additional questions quantified lifetime SHS exposure in the home in years, as previously used by Eisner et al. ${ }^{4}$

\section{CT measures}

Participants underwent whole-lung multidetector helical CT at full inspiration and expiration. Measurements of interest included percentage emphysema, percentage gas-trapping, Pi10 (a measure of airway wall thickness) and airway dimensions including area and diameter of walls and lumens of airways in generations 1-6. Details are provided in the online supplementary material.

\section{Outcomes}

Outcomes of interest were respiratory-specific quality of life (St George's Respiratory Questionnaire (SGRQ)), ${ }^{17}$ general quality of life (short-form 12-item questionnaire, SF12), ${ }^{18}$ exercise capacity (6 min walk distance in metres (6 MWD)), ${ }^{19}$ dyspnoea (modified Medical Research Council questionnaire) ${ }^{20}$ and COPD health status (COPD assessment test, CAT) (see online supplementary e-table 1). ${ }^{21}$ Cough and phlegm over the past day were measured using the total score from the Ease of Cough and Sputum questionnaire. ${ }^{22}$ Respiratory symptoms (cough, phlegm, bronchitis, wheezing and nocturnal symptoms) were measured using the American Thoracic Society Division of Lung Diseases of the National Heart and Lung Institute Questionnaire (ATS/DLD-78-adult). ${ }^{23}$ Chronic cough and phlegm status was determined as an affirmative response to the question "Do you usually...?" for the individual symptom, and chronic productive cough was determined as an affirmative response to both questions, as described previously. ${ }^{24}$ Participants were asked about medication changes or dose adjustments, unscheduled doctor visits, emergency room visits, days hospitalised and intensive care unit admissions for COPD exacerbations and frequency of these instances over the past year. Severe exacerbations were defined as events requiring emergency room visit or hospitalisation. All information was collected at baseline; however, additionally we analysed available data regarding exacerbations noted by participants from the time of study enrolment to most recent follow-up contact.

\section{Statistical methods}

Recent SHS exposure was determined by two exposure metrics including (1) report of living with a smoker (yes/no), referred to as 'living with a smoker', and (2) SHS exposure reported in any location over the past week, dichotomised as $0-1 \mathrm{~h}$ of exposure (non-exposed) or $\geq 2 \mathrm{~h}$ of exposure (exposed) as in previous publications, ${ }^{9}$ referred to as 'recent SHS exposure'. Years of lifetime SHS exposure were also studied and modelled as quartiles of exposure, to evaluate possible dose response. ${ }^{4}$ Participant characteristics were compared based on SHS exposure using $\mathrm{t}$ tests and $\chi^{2}$ tests.

We analysed the relationship between SHS exposures and outcomes using linear and logistic regressions, adjusting for age, gender, race (African American vs other), education (high school education or less vs more than high school), current smoking and pack-years smoked. Cross-sectional data were analysed using linear or logistic regression models (in which coefficients and log odds were the modelled effects) with the exception of analyses of longitudinal exacerbations over follow-up, which were analysed as count data using adjusted Poisson regression (in which relative risk was the modelled effect) and analysis of mean differences in airway wall and lumen area and diameter as well as wall area percentage for generation 1-6 airways, for which we used generalised estimating equations. $^{25}$ Further detail on statistical methods can be found in online supplementary material.

Of interest was possible effect modification of current smoking, such that non-smokers might have relatively higher susceptibility to SHS. In sensitivity analyses, we additionally adjusted these models for the daily number of cigarettes actively smoked to further isolate the effects of SHS over active smoking. We also tested for interactions between SHS exposure and race, gender, severity of airflow obstruction (GOLD 1,2 as less severe vs GOLD 3,4 as more severe) and obesity (defined dichotomously as body mass index $\left.(\mathrm{BMI})>30 \mathrm{~kg} / \mathrm{m}^{2}\right)$.

All analyses were conducted with Stata 12 (Stata Statistical Software: Release 12 (program). College Station, Texas: StataCorp., 2011). p Value $<0.05$ was the threshold for significance for main effects and 0.10 for interactions. ${ }^{15} \quad 26 \quad 27$ SPIROMICS was approved by institutional review boards at each centre and all participants provided written informed consent (ClinicalTrials.gov: NCT01969344).

\section{RESULTS}

At the time of analysis, 1580 participants had spirometric evidence of COPD. Of these participants, 20\% $(n=313)$ reported 
living with a smoker, 54\% $(n=170)$ of whom were current smokers and $46 \%(n=143)$ were former smokers. A total of 428 participants with COPD (27\%) reported recent SHS exposure (ie, $\geq 2$ hours of exposure within the past week), while 1152 (73\%) reported $0-1 \mathrm{~h}$ of exposure. Participants reporting recent SHS exposure had a median of $7 \mathrm{~h}$ of SHS exposure (25th percentile 3, 75th percentile 21, online supplementary e-figure 1). Participants reporting recent SHS exposure were younger (mean age 61.9 vs 66.8 years), more likely to be African American (23\% vs 12\%), had less education and lower household income (table 1). Although there were minimal differences in pack-years smoked, there were more current smokers in the recent SHS exposure group (64\% vs 20\%). Individuals reporting recent SHS had significantly better lung function $\left(\mathrm{FEV}_{1} \%\right.$ predicted 63.5 vs 60.2$)$ and less emphysema and gas-trapping on CT (4.8\% vs $8.1 \%$, and $63.5 \%$ vs $66.9 \%$, respectively). SHS exposure data was missing in only 38 of the 1580 participants, who were excluded from analyses. There were strong correlations between metrics of recent SHS exposure (see online supplementary e-table 2), such that individuals with more reported hours of SHS exposure in the past 7 days were more likely to live with a smoker. Additionally, mean years of SHS exposure reported before and after the age of 18 were significantly higher in the groups reporting more hours of SHS exposure in the past week and living with a smoker. Median follow-up time for exacerbation data was 594 days (25th percentile 292, 75th percentile 995) in the cohort with COPD (strata 3-4).

\section{Association of living with a smoker and outcomes}

After adjustment, living with a smoker was associated with worse outcomes (table 2) including SGRQ, SF12, CAT and higher ease of cough and sputum scores (ie, more impaired). Living with a smoker was also associated with severe exacerbations in the past year and chronic productive cough. Additionally, living with a smoker was associated with increased airway wall thickness measured by Pi10, but not with emphysema or gas-trapping.
Association of recent SHS exposure ( $\geq 2 \mathrm{~h}$ of SHS exposure in the past week) and outcomes

Recent SHS exposure was associated with worse short-term outcomes after adjustment (table 3 and figure 1). Recent SHS was associated with worse SGRQ score, nocturnal symptoms, wheezing, worse ease of cough and phlegm and less exercise capacity. To account for possible influences from occupational exposures, ${ }^{28}$ models were additionally adjusted for report of exposure to vapours, dusts, gases or fumes in the longest-held job, and results were similar. Measures of recent SHS exposure (hours of SHS exposure in the past 7 days and living with a smoker) were associated with differences in airway dimensions (tables 2 and 3). In generation 5 airways, wall area and lumen area and diameter were smaller in those with SHS exposure compared with those without, the wall area was thicker relative to lumen size, as indicated by significantly higher wall area percentage. Results for other airway generations $(1-4,6)$ did not have significant results (data not shown).

\section{Years of SHS exposure and outcomes}

Lifetime exposure to SHS was highly prevalent, with $82.1 \%$ reporting home exposure before age 18 , and $77.8 \%$ reporting home exposure after age 18. Participants were divided into quartiles based on years of home SHS exposure during their lifetime, (median (range): first quartile 18 years (0-18), second quartile 21 years (19-23), third quartile 33 years (24-40) and fourth quartile 52 years.(41-90)). We found minimal contribution of years of cumulative exposure reported with health outcomes in participants with COPD when testing the associations of quartiles 2-4 compared with the first quartile using disjoint categories for each quartile (see online supplementary e-table 3 ). When we tested the overall contribution of years of SHS exposure using likelihood ratio testing of nested models, only the model of SGRQ reached statistical significance $(p=0.047)$ in its overall contribution to the model.

\section{Subgroups with increased susceptibility to SHS}

We found interactions between SHS metrics and smoking status, obesity and severity of airflow obstruction. Current smoking modified the effect of SHS exposure on several outcomes
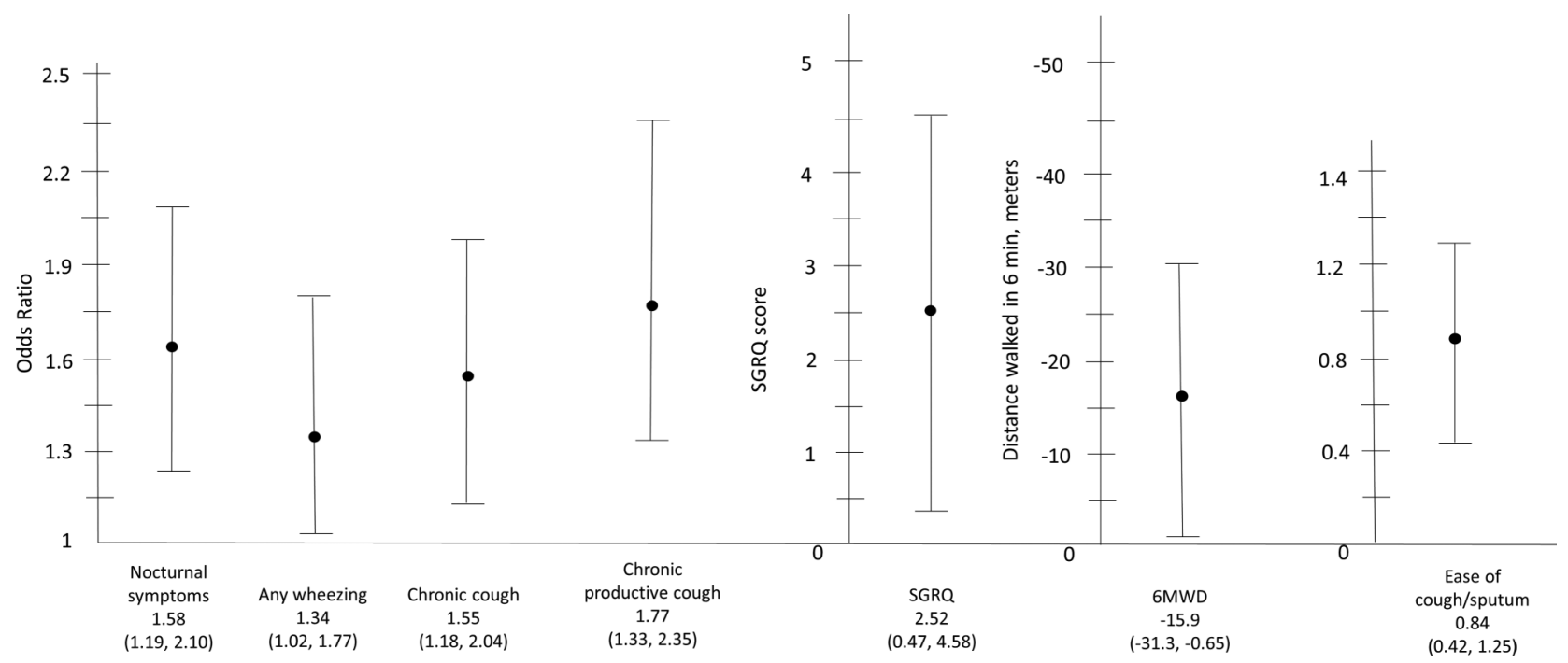

Figure 1 Impact of hours of second-hand smoke (SHS) exposure in the past week on health outcomes in all participants with COPD is shown. Modelled estimates shown are for $\geq 2 \mathrm{~h}$ of recent SHS exposure compared with participants with $0-1 \mathrm{~h}$ of exposure. 6MWD, 6 min walk distance in metres; SGRQ, St George's Respiratory Questionnaire. 
Table 1 Characteristics of GOLD 1-4 participants, by hours of second-hand smoke exposure per week

\begin{tabular}{|c|c|c|c|}
\hline & $\begin{array}{l}0-1 \text { hours of SHS exposure in a } \\
\text { week }(n=1152)\end{array}$ & $\begin{array}{l}2+h \text { SHS exposure per } \\
\text { week }(n=428)\end{array}$ & p Value \\
\hline Age (years) & $66.8(7.41)$ & $61.9(8.27)$ & $<0.0001$ \\
\hline Female, $n(\%)$ & $506(44 \%)$ & $165(39 \%)$ & 0.055 \\
\hline African American, $n(\%)$ & $136(12 \%)$ & $98(23 \%)$ & $<0.0001$ \\
\hline Hispanic ethnicity, $\mathrm{n}(\%)$ & $42(4 \%)$ & $19(4 \%)$ & 0.467 \\
\hline $\mathrm{FEV}_{1} \%$ predicted & $60.19(23.75)$ & $63.53(21.66)$ & 0.013 \\
\hline GOLD categories, n (\%) & & & 0.016 \\
\hline 1 & $248(22 \%)$ & $103(24 \%)$ & \\
\hline 2 & $491(43 \%)$ & $208(49 \%)$ & \\
\hline 3 & $288(25 \%)$ & $84(20 \%)$ & \\
\hline 4 & $125(11 \%)$ & $33(8 \%)$ & \\
\hline Oxygen use, $\mathrm{n}(\%)$ & $268(23 \%)$ & $55(13 \%)$ & $<0.0001$ \\
\hline Current inhaled steroid use & $555(49 \%)$ & $192(45 \%)$ & 0.237 \\
\hline BMI & $27.49(5.20)$ & $27.17(5.58)$ & 0.301 \\
\hline Pack-years smoked* & $48.5(36,66)$ & $48(37,64.5)$ & 0.557 \\
\hline Current smoker, n (\%) & $229(20 \%)$ & $276(64 \%)$ & $<0.0001$ \\
\hline$>$ High school education, $\mathrm{n}(\%)$ & $749(65 \%)$ & $219(51 \%)$ & $<0.0001$ \\
\hline Income $\$ 75 \mathrm{~K} /$ year or more, $\mathrm{n}(\%)$ & $215(24 \%)$ & $55(15 \%)$ & 0.001 \\
\hline Obesity, $n(\%)$ & $358(31 \%)$ & $138(32 \%)$ & 0.657 \\
\hline$\%$ gas trapping & $66.93(13.73)$ & $63.52(14.43)$ & $<0.0001$ \\
\hline$\%$ emphysema* & $8.07(2.73,19.1)$ & $4.82(1.82,12.59)$ & $<0.0001$ \\
\hline Pi 10 all airways & $3.71(0.08)$ & $3.73(0.09)$ & 0.011 \\
\hline
\end{tabular}

*Values displayed are median (25th percentile, 75th percentile). All other values are mean (SD) unless otherwise indicated.

BMI, body mass index; GOLD, Global initiative for obstructive lung disease; SHS, second-hand smoke.

Table 2 Associations of living with a smoker and COPD outcomes in SPIROMICS

\begin{tabular}{|c|c|c|c|}
\hline Linear regression models & Absolute difference & $95 \% \mathrm{Cl}$ & $\mathrm{p}$ Value \\
\hline $6 \mathrm{MWD}, \mathrm{m}$ & -7.68 & $(-23.50$ to 8.15$)$ & 0.341 \\
\hline $\mathrm{FEV}_{1} \%$ predicted & -2.13 & $(-4.87$ to 0.62$)$ & 0.129 \\
\hline SGRQ score & 3.10 & (0.99 to 5.21$)$ & 0.004 \\
\hline SF12 GH score & -1.53 & $(-2.90$ to -0.16$)$ & 0.029 \\
\hline CAT score & 1.43 & (0.52 to 2.35$)$ & 0.002 \\
\hline mMRC score & 0.07 & $(-0.05$ to 0.20$)$ & 0.223 \\
\hline Ease of Cough and Sputum score in past day & 0.76 & (0.34 to 1.19$)$ & $<0.0001$ \\
\hline$\%$ emphysema & 0.35 & $(-0.92$ to 1.55$)$ & 0.573 \\
\hline$\%$ gas-trapping & 0.06 & $(-1.65$ to 1.88$)$ & 0.946 \\
\hline Pi 10 (all airways) & 0.16 & (0.03 to 0.29$)$ & 0.020 \\
\hline \multicolumn{4}{|l|}{ Airway dimensions (fifth generation airways) } \\
\hline Wall area percentage & 0.431 & $(0.023$ to 0.840$)$ & 0.039 \\
\hline Wall area & -0.79767 & $(-1.64367$ to 0.04832$)$ & 0.065 \\
\hline Lumen area & -1.08644 & $(-2.00936$ to -0.16352$)$ & 0.021 \\
\hline Lumen diameter & -0.0799 & ( -0.1697 to 0.0098$)$ & 0.081 \\
\hline Logistic regression models & OR & $95 \% \mathrm{Cl}$ & $\mathrm{p}$ Value \\
\hline Nocturnal symptoms & 1.17 & (0.87 to 1.57$)$ & 0.295 \\
\hline Any wheezing & 1.16 & (0.86 to 1.54 ) & 0.325 \\
\hline Chronic cough & 1.41 & (1.06 to 1.87$)$ & 0.019 \\
\hline Chronic productive cough & 1.71 & (1.28 to 2.30$)$ & $<0.0001$ \\
\hline Exacerbation risk in past year & 1.11 & (0.81 to 1.51$)$ & 0.511 \\
\hline Severe exacerbation risk in past year & 1.51 & (1.04 to 2.17$)$ & 0.029 \\
\hline Poisson models & $\mathbf{R R}$ & $95 \% \mathrm{Cl}$ & $\mathrm{p}$ Value \\
\hline Exacerbations experienced over follow-up & 1.04 & (0.84 to 1.30$)$ & 0.696 \\
\hline Severe exacerbations experienced over follow-up & 1.11 & (0.82 to 1.52$)$ & 0.497 \\
\hline
\end{tabular}

Bold indicates statistically significant findings at $\mathrm{P}<0.05$ level.

Adjusted for age, gender, race, $\mathrm{FEV}_{1} \%$ predicted (except for analysis of $\mathrm{FEV}_{1} \%$ predicted), education level, current smoking status, oxygen use and pack-years smoked. Measures of airway dimensions additionally adjusted for total lung volume achieved at CT. Poisson models of exacerbations and severe exacerbations over follow-up additionally adjusted for follow-up time.

6 MWD, 6 min walk distance; CAT, COPD assessment test; mMRC, modified Medical Research Council questionnaire; RR, relative risk; SF12 GH, Medical outcomes short-form 12 -item questionnaire general health score; SGRQ, St George's Respiratory Questionnaire; SPIROMICS, subpopulations and intermediate outcomes of COPD Study. 
(figure 2 and table 4), such that in most cases current smokers appeared to have higher susceptibility to adverse outcomes than former smokers. Living with a smoker was linked to a higher risk of a severe COPD exacerbation in the past year in current smokers compared with former smokers (OR 2.33 vs 1.12, interaction $\mathrm{p}=0.055)$. Recent SHS exposure had a greater negative impact on $6 \mathrm{MWD}$ in current smokers compared with former smokers $(-27.41$ vs -5.96 , interaction $p=0.071)$; however, only general quality of life was worse in former smokers compared with active smokers (SF12 -2.93 vs 0.68 , interaction $\mathrm{p}=0.006)$. Models including adjustment for number of daily cigarettes smoked did not appreciably change the effect of SHS among those still smoking (data not shown).

Those with milder airflow limitation and obese individuals had greater adverse effects associated with SHS exposure for some outcomes (figures 3 and 4, table 4). Living with a smoker was associated with worse outcomes among participants with less severe air flow obstruction (GOLD 1-2) compared with those with more severe obstruction (GOLD 3-4), including greater decrement in exercise capacity, worse CAT score and more wheezing. Among obese individuals, living with a smoker was linked with a higher risk of nocturnal symptoms and chronic cough compared with non-obese individuals. Additionally, recent SHS exposure was associated with worse quality of life among obese individuals compared with non-obese individuals, though no such association was noted for SGRQ. We found no significant interactions with gender or race.

\section{Impact of SHS exposure on outcomes in non-smokers and current and former smokers without COPD}

Analyses of recent SHS exposure and living with a smoker were also performed similarly in the cohort of healthy non-smokers (stratum 1, $n=193$ ) and the cohort of former and current smokers without COPD (stratum 2, $\mathrm{n}=803$ ) and results are displayed in online supplementary e-tables 4 and 5. There were fewer statistically significant associations of recent SHS exposure and living with a smoker with outcomes in stratum 1, likely reflecting the small size of the cohort and relative low prevalence of reported SHS exposure (only in 12\%); however, several significant associations were present within stratum 2, illustrating further the importance of SHS in influencing respiratory symptoms in the general population as well as those with COPD.

\section{DISCUSSION}

SHS is an unfortunately common exposure among individuals with COPD. We have shown that SHS is a significant contributor to adverse outcomes in COPD, even among active smokers, in a large, well-characterised cohort of patients with a wide range of COPD severity. Recent SHS exposure and living with a smoker are associated with worse respiratory symptoms, quality of life and relative airway wall thickness in COPD. Living with a smoker is also associated with risk of severe exacerbations. Importantly, SHS is linked to worse outcomes even among active smokers. In addition, obese individuals and individuals with less severe COPD may be more susceptible to the adverse effects of SHS.

About $20 \%$ reported living with a smoker and $36 \%$ of participants with COPD reported $\geq 2 \mathrm{~h}$ of recent SHS exposure, significantly higher than the Centers for Disease Control and Prevention (CDC)'s estimates that 5.4\% of non-smoking adults are exposed to SHS at home. ${ }^{29}$ Such findings highlight the extraordinary prevalence of SHS exposure in COPD. Recent SHS exposure was associated with higher risk of adverse outcomes in COPD, including lower exercise capacity, worse quality of life and more respiratory symptoms. Owing to the large size of SPIROMICS, our findings lend substantial weight to the findings of previous studies ${ }^{8}{ }^{9}$ which have shown that

Table 3 Associations of $\geq 2 \mathrm{~h}$ of SHS exposure in past week with COPD outcomes in SPIROMICS

\begin{tabular}{|c|c|c|c|}
\hline \multicolumn{4}{|l|}{$\begin{array}{l}\text { Linear regression models } \\
\text { Hours of SHS smoke in the past } 7 \text { day } \\
0-1 \mathrm{~h} \text { (REF) } \\
2+\mathrm{h}\end{array}$} \\
\hline $6 \mathrm{MWD}, \mathrm{m}$ & -15.9 & $(-31.33$ to -0.65$)$ & 0.041 \\
\hline SGRQ score & 2.52 & $(0.47$ to 4.58$)$ & 0.016 \\
\hline SF12 GH score & -1.17 & $(-2.50$ to 0.16$)$ & 0.084 \\
\hline CAT score & 0.82 & $(-0.06$ to 1.71$)$ & 0.068 \\
\hline mMRC score & 0.097 & $(-0.018$ to 0.21$)$ & 0.098 \\
\hline Ease of Cough and Sputum total score & 0.84 & (0.42 to 1.25$)$ & $<0.0001$ \\
\hline Pi10 (all airways) & 0.18 & (0.05 to 0.31$)$ & 0.006 \\
\hline \multicolumn{4}{|l|}{ Airway dimensions (fifth generation airways) } \\
\hline Wall area percentage & 0.432 & $(0.048$ to 0.816$)$ & 0.027 \\
\hline Wall area & -0.67611 & $(-1.47355$ to 0.12133$)$ & 0.097 \\
\hline Lumen area & -0.89061 & $(-1.76076$ to -0.02046$)$ & 0.045 \\
\hline Lumen diameter & -0.07514 & $(-0.1597$ to 0.00939$)$ & 0.081 \\
\hline Logistic regression models & $\mathrm{OR}$ & $95 \% \mathrm{Cl}$ & p Value \\
\hline Nocturnal symptoms & 1.58 & (1.19 to 2.10$)$ & 0.001 \\
\hline Any wheezing & 1.34 & (1.02 to 1.77$)$ & 0.039 \\
\hline
\end{tabular}




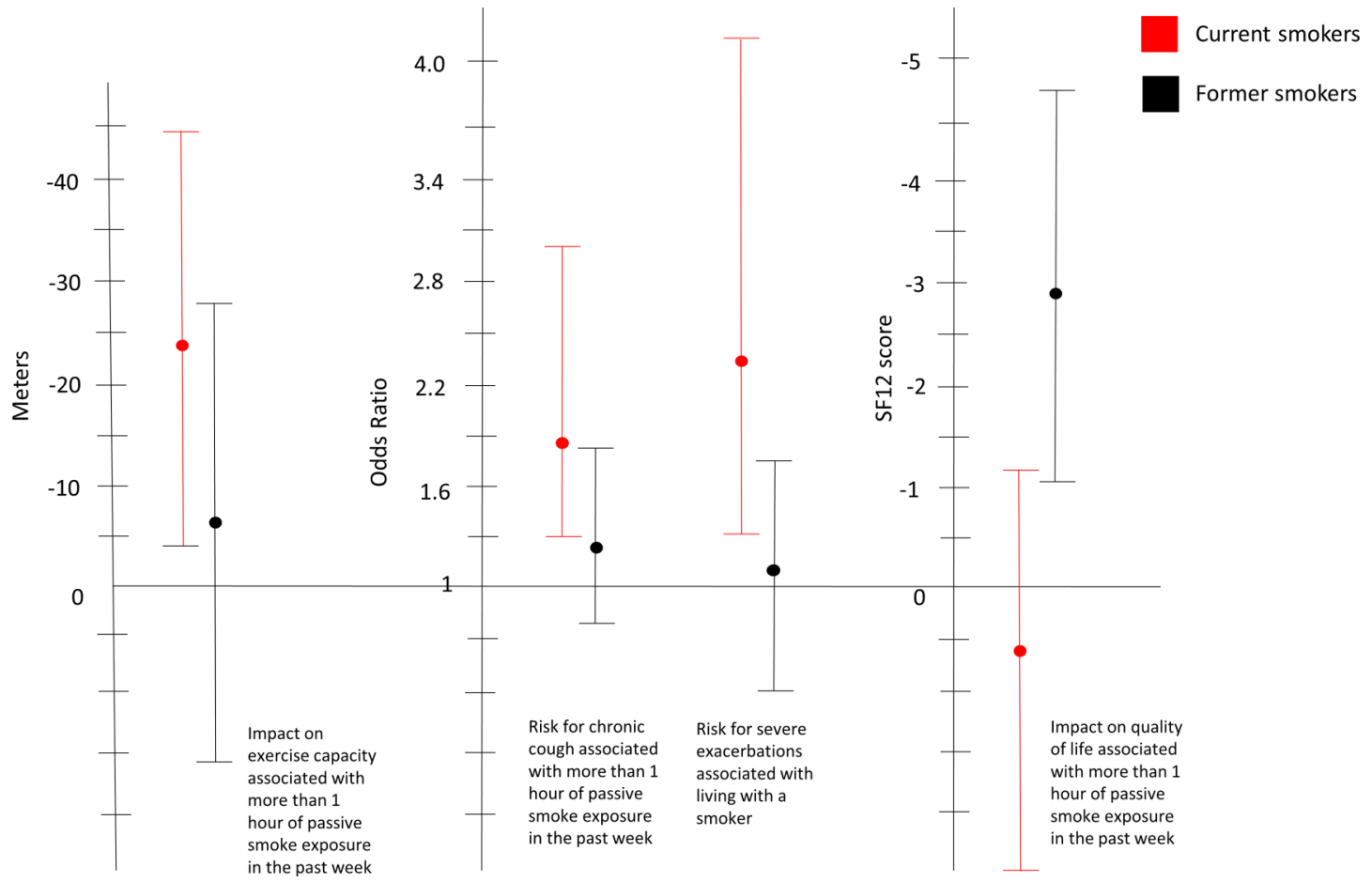

Figure 2 Interactions between current smoking and second-hand smoke exposure in COPD. SF12, short-form 12-item questionnaire.

higher levels of SHS exposure are associated with worse health status, quality of life, dyspnoea, exercise capacity and healthcare usage in former smokers with COPD. Further, we were able to test these associations in a well-characterised population with COPD with a high burden of smoke exposure (>20 pack-years) and also demonstrated that the associations between SHS and

Table 4 Significant interactions between SHS exposure and smoking status, obesity, severity of airflow obstruction

\begin{tabular}{|c|c|c|c|c|c|c|c|}
\hline & $\boldsymbol{\beta}$ & $95 \% \mathrm{Cl}$ & p Value & $\boldsymbol{\beta}$ & $95 \% \mathrm{Cl}$ & \multicolumn{2}{|l|}{$\mathrm{p}$ Value } \\
\hline \multicolumn{8}{|c|}{ Interactions with current smoking (correspond to figure 2) } \\
\hline & \multicolumn{3}{|c|}{$\begin{array}{l}\text { Impact of } 2+h \text { recent SHS exposure } \\
\text { on current smokers }\end{array}$} & \multicolumn{3}{|c|}{$\begin{array}{l}\text { Impact of } 2+h \text { recent SHS exposure } \\
\text { on former smokers }\end{array}$} & P(int \\
\hline 6 min walk distance & -24.41 & $(-44.81$ to -4.01$)$ & 0.019 & -5.96 & $(-27.90$ to 15.97$)$ & 0.594 & 0.071 \\
\hline SF12 GH quality of life score & 0.68 & $(-1.22$ to 2.59$)$ & 0.481 & -2.93 & $(-4.76$ to -1.08$)$ & 0.002 & 0.006 \\
\hline \multirow[t]{2}{*}{ Chronic cough, OR } & 2.00 & (1.32 to 3.02$)$ & $<0.0001$ & 1.26 & (0.86 to 1.85$)$ & 0.238 & 0.083 \\
\hline & \multicolumn{3}{|c|}{$\begin{array}{l}\text { Impact of living with a smoker on current } \\
\text { smokers }\end{array}$} & \multicolumn{3}{|c|}{$\begin{array}{l}\text { Impact of living with a smoker on former } \\
\text { smokers }\end{array}$} & P(int \\
\hline Severe exacerbation risk past year, OR & 2.33 & (1.30 to 4.18$)$ & 0.004 & 1.12 & (0.67 to 1.86$)$ & 0.665 & 0.055 \\
\hline SF12GH quality of life score & -3.42 & $(-5.76$ to -1.09$)$ & 0.004 & -0.06 & $(-1.68$ to 1.57$)$ & 0.945 & 0.085 \\
\hline \multicolumn{8}{|c|}{ Interactions with obesity (correspond to figure 3 ) } \\
\hline & \multicolumn{3}{|c|}{$\begin{array}{l}\text { Impact of } 2+h \text { recent SHS exposure on obese } \\
\text { participants }\end{array}$} & \multicolumn{3}{|c|}{$\begin{array}{l}\text { Impact of } 2+h \text { recent SHS exposure on } \\
\text { non-obese participants }\end{array}$} & P(int \\
\hline \multirow[t]{2}{*}{ SF12GH quality of life score } & -3.42 & $(-5.76$ to -1.09$)$ & 0.004 & -0.06 & $(-1.68$ to 1.57$)$ & 0.945 & 0.085 \\
\hline & \multicolumn{3}{|c|}{$\begin{array}{l}\text { Impact of living with a smoker on obese } \\
\text { participants }\end{array}$} & \multicolumn{4}{|c|}{$\begin{array}{l}\text { Impact of living with a smoker on non-obese } \\
\text { participants }\end{array}$} \\
\hline Nocturnal symptoms, OR & 1.78 & (1.04 to 3.04$)$ & 0.036 & 0.97 & (0.68 to 1.38$)$ & 0.863 & 0.030 \\
\hline Chronic cough, OR & 2.10 & (1.23 to 3.58$)$ & 0.007 & 1.16 & (0.83 to 1.64$)$ & 0.384 & 0.035 \\
\hline \multicolumn{8}{|c|}{ Interactions with disease severity (correspond to figure 4) } \\
\hline & \multicolumn{3}{|c|}{$\begin{array}{l}\text { Impact of living with a smoker on GOLD 1-2 } \\
\text { participants }\end{array}$} & \multicolumn{4}{|c|}{$\begin{array}{l}\text { Impact of living with a smoker on GOLD 3-4 } \\
\text { participants }\end{array}$} \\
\hline 6 min walk distance & -20.13 & $(-38.34$ to -1.91$)$ & 0.030 & 10.05 & $(-21.79$ to 41.89$)$ & 0.535 & 0.027 \\
\hline Total CAT score, measure of health status & 2.04 & $(0.86$ to 3.22$)$ & 0.001 & 0.23 & $(-1.34$ to 1.80$)$ & 0.774 & 0.075 \\
\hline Any wheezing, OR & 1.42 & $(1.00$ to 2.02$)$ & 0.050 & 0.84 & (0.53 to 1.33 ) & 0.457 & 0.040 \\
\hline
\end{tabular}


Figure 3 Interactions between obesity and second-hand smoke exposure in COPD. SF12, short-form 12 -item questionnaire.

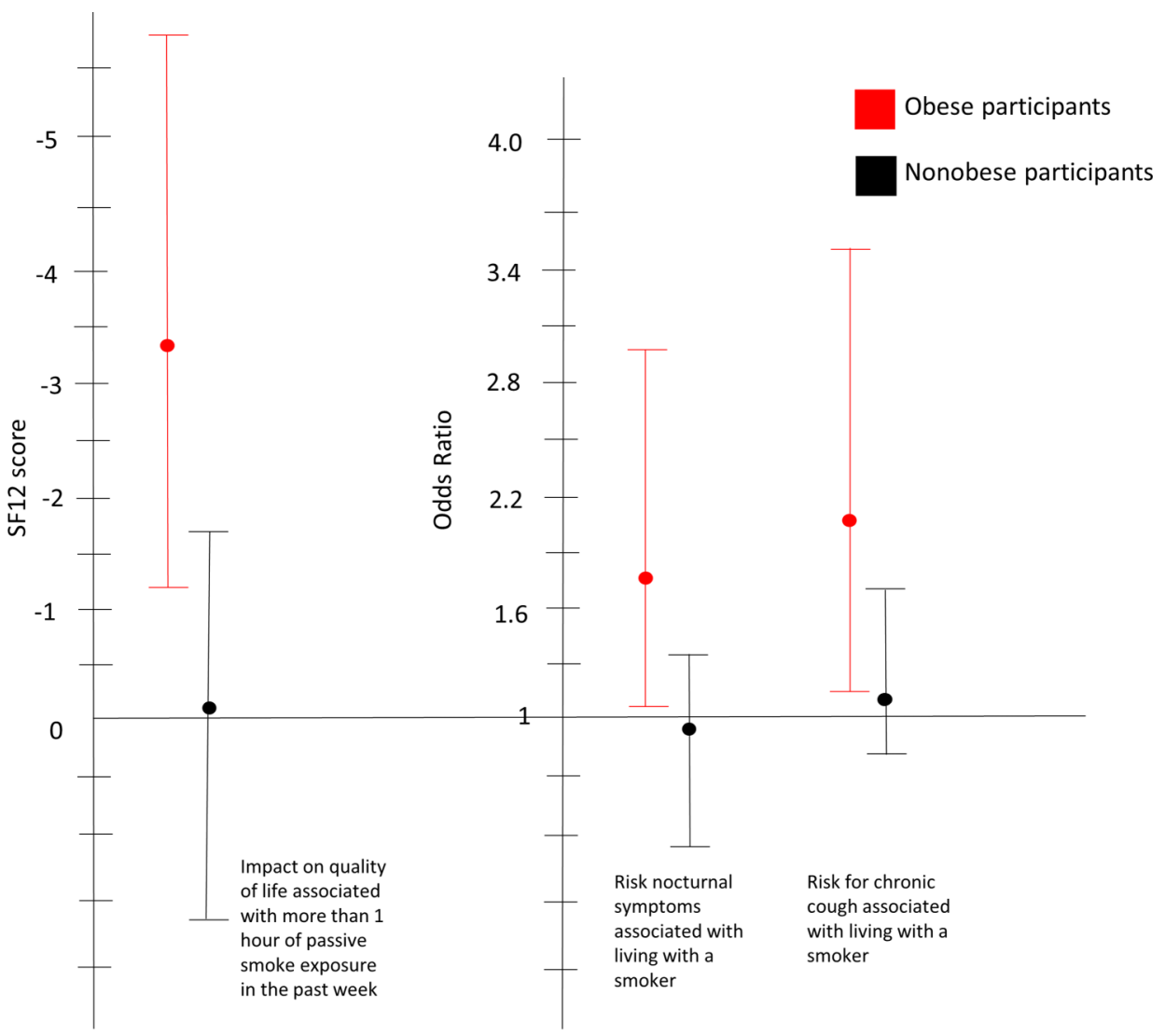

negative health outcomes were also present in former and current smokers without COPD, also lending weight to our findings that SHS is an important risk factor for adverse outcomes.

To our knowledge, our results are the first to show the association of SHS with greater relative airway wall thickness in COPD, a novel finding which correlates with chronic bronchitic symptoms. ${ }^{30}{ }^{31}$ These findings were shown using two distinct techniques: Pi10 and using generation-specific airway lumen and wall data. Though these latter findings were only noted in generation 5 airways, previously, Smith et al reported significant changes in generation 4-6 airways in the population with COPD when compared with strata 1-2 individuals. It is likely that we were unable to see differences in generations other than 5 because of the smaller sample size studied (COPD participants only) and the limited variability in airway dimensions in the population with COPD when compared with studying the larger cohort. Experimental models of SHS exposure in rats

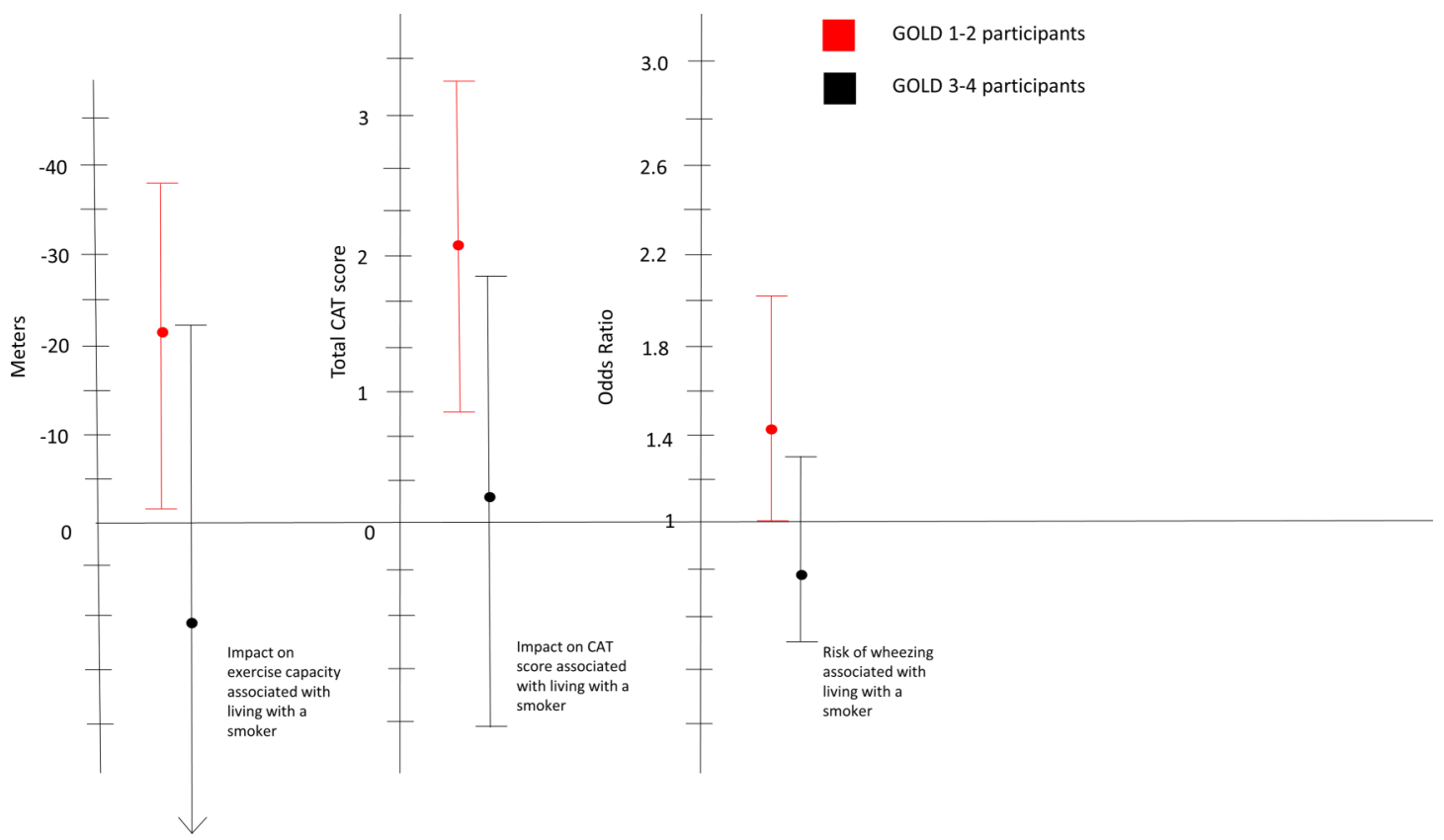

Figure 4 Interactions between severity of COPD and second-hand smoke exposure in COPD. 
have shown heightened pulmonary inflammation leading ultimately to airway and airspace remodelling. ${ }^{32}$ The mechanisms for airways and airspace injury due to SHS have not been clearly established among individuals or in animal models where COPD pre-exists, and would be the next step in order to better explain the findings of our study. Importantly, our findings are consistent with those of general population studies which have shown a higher risk of chronic bronchitis in non-smokers exposed to SHS. ${ }^{133}$

Finally, we have shown that there are possibly subgroups of individuals with COPD that experience higher susceptibility to the health effects of SHS exposure. We hypothesised that former smokers would be more sensitive to SHS than current smokers. This was not the case. For some outcomes such as quality of life, current smokers showed a greater impact of SHS compared with former smokers. One might intuit that SHS exposure would not greatly impact actively smoking individuals, given the small burden that SHS represents when compared with the extensive burden of primary smoking. However, our findings suggest that it is possible that current smokers experience worse outcomes related to SHS possibly because they have a longer duration (though no difference in pack-years smoked, there is a possibility of more hours of active and passive smoke exposure in any given day) or concentration of smoke exposure, as opposed to the quantity of exposure. Additionally, it is important to consider that the toxicity of SHS is qualitatively and quantitatively different from direct active smoke exposure and as such has different effects on outcomes in COPD. Though most of the compounds emitted in SHS are similar to those in mainstream smoke, the quantitative makeup of SHS and mainstream smoke has been shown to differ. In some cases, the concentration of certain compounds in SHS is greater than that of mainstream smoke, that is, nicotine, ammonia, formaldehyde, and in other cases, that is, $\mathrm{N}^{\prime}$-nitrosonornicotine, (methylnitrosamino)-1-(3pyridyl)-1-butanone, the opposite is true. Additionally, the makeup of SHS is often greatly impacted by other environmental exposures. ${ }^{74}$ Such variation in the quantitative burden of certain compounds could potentially explain our paradoxical findings with regard to current and former smokers with COPD. It is also possible that active smokers have heightened airway inflammation and resulting damage to epithelial cells that alter susceptibility to further inflammation and damage due to SHS. It is possible that SHS is a marker for other behaviours such as medication adherence, exercise or other habits which are less favourable to overall health. The mechanism is an important target for further study, but it also highlights the clinical and public health importance of minimising SHS exposure in all individuals regardless of smoking status.

Obese individuals also showed heightened susceptibility to SHS, with a higher risk of nocturnal symptoms, chronic cough and poor quality of life as a result of SHS compared with lean individuals. These findings are consistent with recently published findings showing obesity as a susceptibility factor for adverse health outcomes related to indoor air pollution in both COPD $^{15}$ and asthma. ${ }^{35}$ To our knowledge this is the first study showing that obesity may be a susceptibility factor for adverse outcomes associated with SHS. The increased inflammation associated with fat, specifically visceral adipose tissue, may lead to higher amounts of systemic and airway inflammation and may lead to alterations in immune defences in the lung leading to worse outcomes as a result of pollutant exposure. ${ }^{36}$ Additionally, obesity may be a reflection of more time spent at home (exposed to home SHS), or also a high fat, low antioxidant diet which has been shown to be proinflammatory. ${ }^{37}$ Whatever the mechanism, our findings lend weight to the necessity for further studies of obesity as a susceptibility factor for pollutant exposure in lung disease. We also found that individuals with less severe airflow limitation (GOLD stage 1-2 participants) had slightly more susceptibility to adverse outcomes due to SHS than participants with more severe airflow limitation (GOLD stage 3-4 participants). Though this finding is seemingly counterintuitive, it is plausible that individuals with worse COPD severity have such negative outcomes that detecting a further negative effect of SHS would be difficult. It is also possible that individuals with more severe COPD adopt avoidance behaviours that would attenuate the burden of SHS exposure despite having the same amount of exposure as gauged by our metrics of SHS exposure.

Our study is subject to some limitations. Our measures of SHS exposure rely on self-report, and there is a possibility of measurement error. We used a questionnaire that has been previously validated and shown to be associated with health outcomes. Additionally, our findings were consistent across two measures of SHS exposure (living with a smoker and SHS over the past week), further demonstrating their robustness. We were unable to find an association between years of previous SHS exposure and COPD health outcomes. We were similarly unable to find an association between SHS and percentage emphysema and gas trapping on CT. It is not clear why shorter-term exposures seemed to have more impact than longer-term exposures. It is possible that, in the short term, individuals with COPD including active smokers are susceptible to the acute inflammatory effects of SHS, but in the long term, primary smoking outweighs the effect of SHS on progression of COPD. It is also possible that longer-term measures are more subject to recall bias. In addition, this study is subject to the limitations of a cross-sectional study design including issues of temporality and causality. For example, perhaps individuals with more symptoms or more severe disease are more likely to live with a smoker or have a higher risk of SHS exposure. We used available longitudinal data on exacerbations experienced over follow-up but found no significant associations at this point. It will be important to reconsider this question once more complete follow-up data are available after the conclusion of the study to better understand the risk of longitudinal exacerbations associated with SHS exposure. Additionally, though we controlled our models for active smoking in multiple ways, we acknowledge the possibility of residual confounding. Finally, as with many observational studies with multiple clinical outcomes of interest, we are limited by the number of statistical comparisons made in that this can increase the possibility of a type I error. Despite this, the consistency of our findings for the comparisons made is notable. Limitations can be addressed as more longitudinal data become available in SPIROMICS. Our findings are relatively generalisable to the population with COPD in the USA, owing to the diversity and broad range of disease in SPIROMICS.

In summary, using the well-characterised COPD cohort in SPIROMICS, we have shown that SHS exposure is common, impacting over a quarter of the population with COPD. Such exposure is associated with higher risk of adverse outcomes in former smokers and in those currently smoking, and also with a distinct pattern on CT indicative of heightened airway inflammation. Finally, we have shown that SHS has important impacts on obese individuals and surprisingly also current active smokers, findings which challenge us to further understand the mechanisms responsible for adverse outcomes in COPD associated with SHS exposure. ${ }^{38}$ 


\section{Author affiliations}

${ }^{1} J o h n s$ Hopkins University School of Medicine, Baltimore, Maryland, USA

${ }^{2}$ Columbia University School of Medicine, New York, New York, USA

${ }^{3}$ University of Michigan School of Medicine, Ann Arbor, Michigan, USA

${ }^{4}$ University of California San Francisco School of Medicine, San Francisco,

California, USA

${ }^{5}$ Wake Forest University Center for Genomics and Personalized Medicine Research, Winston-Salem, North Carolina, USA

${ }^{6}$ University of Utah Health Sciences Center, Salt Lake City, Utah, USA

${ }^{7}$ Weill Cornell Medical College, New York City, New York, USA

${ }^{8}$ University of California Los Angeles, David Geffen School of Medicine, Los Angeles, California, USA

${ }^{9}$ National Jewish Health, Denver, Colorado, USA

${ }^{10}$ Genentech, Inc., South San Francisco, California, USA

${ }^{11}$ University of Nebraska Medical Center, Omaha, Nebraska, USA

Acknowledgements The authors thank the SPIROMICS participants and participating physicians, investigators and staff for making this research possible. More information about the study and how to access SPIROMICS data is at http:// www.spiromics.org. They would like to acknowledge the following current and former investigators of the SPIROMICS sites and reading centres: Neil E Alexis, PhD; Wayne H Anderson, PhD; R Graham Barr, MD, DrPH; Eugene R Bleecker, MD; Richard C Boucher, MD; Russell P Bowler, MD, PhD; Elizabeth E Carretta, MPH; Stephanie A Christenson, MD; Alejandro P Comellas, MD; Christopher B Cooper, MD, PhD; David J Couper, PhD; Gerard J Criner, MD; Ronald G Crystal, MD; Jeffrey L Curtis, MD; Claire M Doerschuk, MD; Mark T Dransfield, MD; Christine M Freeman, PhD; MeiLan K Han, MD, MS; Nadia N Hansel, MD, MPH; Annette T Hastie, PhD; Eric A Hoffman, PhD; Robert J Kaner, MD; Richard E Kanner, MD; Eric C Kleerup, MD; Jerry A Krishnan, MD, PhD; Lisa M LaVange, PhD; Stephen C Lazarus, MD; Fernando J Martinez, MD, MS; Deborah A Meyers, PhD; John D Newell Jr, MD; Elizabeth C Oelsner, MD, MPH; Wanda K O'Neal, PhD; Robert Paine, III, MD; Nirupama Putcha, MD, MHS; Stephen I. Rennard, MD; Donald P Tashkin, MD; Mary Beth Scholand, MD; J Michael Wells, MD; Robert A Wise, MD and Prescott G Woodruff, MD, MPH. The project officers from the Lung Division of the National Heart, Lung, and Blood Institute were Lisa Postow, PhD, and Thomas Croxton, PhD, MD.

Contributors All authors contributed to data analysis and interpretation, critical revisions of intellectual contact, approval of the version to be published and all authors are accountable for all aspects of this work.

Funding NP was supported by the Johns Hopkins University Clinician Scientist Award, the Pearl M. Stetler Research Foundation Award during the conduct of this work and is currently supported by NIH/NHLBI 5K23HL123594-02. SPIROMICS is funded by the National Heart, Lung, and Blood Institute (NHLBI) of the $\mathrm{NIH}$, contract and grant numbers: HHSN268200900013C, HHSN268200900014C, HHSN268200900015C, HHSN268200900016C, HHSN268200900017C, HHSN268200900018C, HHSN2682009000019C and HHSN268200900020C, which were supplemented by contributions made through the Foundation for the NIH from AstraZeneca; Bellerophon Pharmaceuticals; Boehringer-Ingelheim Pharmaceuticals; Chiesi Farmaceutici SpA; Forest Research Institute; GSK; Grifols Therapeutics; Ikaria; Nycomed GmbH; Takeda Pharmaceutical Co; Novartis Pharmaceuticals Corp; Regeneron Pharmaceuticals and Sanofi.

Competing interests DPT has provided consulting services for AstraZeneca, Sunovion, Mylan, Novartis, Glenmark, Theravance; has been a speaker for AstraZeneca, Sunovion and Boehringer-Ingelheim and has received research grants from Boehringer-Ingelheim, Sunovion and GlaxoSmithKline. The remainder of the authors report no significant interests to disclose.

Ethics approval Institutional review boards at all respective clinical sites for SPIROMICS: Johns Hopkins University, Columbia University, University of Utah, University of California San Diego, National Jewish Hospital, University of Alabama Birmingham, University of North Carolina, Wake Forest University, University of Michigan, Temple University, University of Illinois, University of lowa and University of California Los Angeles.

Provenance and peer review Not commissioned; externally peer reviewed.

Data sharing statement Data used in the present study are from an ongoing prospective cohort study of COPD. Persons interested in using data from this studies should contact the corresponding author or visit the study website.

\section{REFERENCES}

1 Samet JM. The Surgeon Generals' reports and respiratory diseases. From 1964 to 2014. Ann Am Thorac Soc 2014;11:141-8.

2 Eisner MD, Wang Y, Haight TJ, et al. Secondhand smoke exposure, pulmonary function, and cardiovascular mortality. Ann Epidemiol 2007;17: 364-73.
3 Eisner MD. Secondhand smoke and obstructive lung disease: a causal effect? Am J Respir Crit Care Med 2009:179:973-4.

4 Eisner MD, Balmes J, Katz PP, et al. Lifetime environmental tobacco smoke exposure and the risk of chronic obstructive pulmonary disease. EnvironHealth 2005;4:7

5 Yin $\mathrm{P}$, Jiang $\mathrm{CQ}$, Cheng $\mathrm{KK}$, et al. Passive smoking exposure and risk of COPD among adults in China: the Guangzhou Biobank Cohort Study. Lancet 2007:370:751-7.

6 Sezer H, Akkurt I, Guler N, et al. A case-control study on the effect of exposure to different substances on the development of COPD. Ann Epidemiol 2006;16: 59-62.

7 US Department of Health and Human Services. The Health Consequences of Involuntary Exposure to Tobacco Smoke: A Report of the Surgeon General. Atlanta, GA: U.S. Department of Health and Human Services, Centers for Disease Control and Prevention, Coordinating Center for Health Promotion, National Center for Chronic Disease Prevention and Health Promotion, Office of Smoking and Health, 2006.

8 Eisner MD, Balmes J, Yelin EH, et al. Directly measured secondhand smoke exposure and COPD health outcomes. BMC Pulm Med 2006:6:12

9 Eisner MD, Iribarren C, Yelin EH, et al. The impact of SHS exposure on health status and exacerbations among patients with COPD. Int I Chron Obstruct Pulmon Dis 2009:4:169-76

10 Eisner MD, Jacob P III, Benowitz NL, et al. Longer term exposure to secondhand smoke and health outcomes in COPD: impact of urine 4-(methylnitrosamino)-1(3-pyridyl)-1-butanol. Nicotine Tob Res 2009;11:945-53.

11 Rabe KF, Hurd S, Anzueto A, et al. Global strategy for the diagnosis, management, and prevention of chronic obstructive pulmonary disease: GOLD executive summary. AmJRespirCrit Care Med 2007;176:532-55.

12 Couper D, LaVange LM, Han M, et al. Design of the Subpopulations and Intermediate Outcomes in COPD Study (SPIROMICS). Thorax 2014;69: 491-4.

13 Dransfield MT, Davis JJ, Gerald LB, et al. Racial and gender differences in susceptibility to tobacco smoke among patients with chronic obstructive pulmonary disease. Respir Med 2006;100:1110-16.

14 Chatila WM, Wynkoop WA, Vance G, et al. Smoking patterns in African Americans and whites with advanced COPD. Chest 2004;125:15-21.

15 McCormack MC, Belli AJ, Kaji DA, et al. Obesity as a susceptibility factor to indoor particulate matter health effects in COPD. Eur Respir J 2015;45:1248-57.

16 Eisner MD, Katz PP, Yelin EH, et al. Measurement of environmental tobacco smoke exposure among adults with asthma. Environ Health Perspect 2001;109:809-14.

17 Jones PW, Quirk FH, Baveystock CM, et al. A self-complete measure of health status for chronic airflow limitation. The St. George's Respiratory Questionnaire. Am Rev Respir Dis 1992:145:1321-7.

18 Ware J Jr, Kosinski M, Keller SD. A 12-Item Short-Form Health Survey: construction of scales and preliminary tests of reliability and validity. Med Care 1996:34:220-33.

19 Holland AE, Spruit MA, Troosters T, et al. An official European Respiratory Society/ American Thoracic Society technical standard: field walking tests in chronic respiratory disease. Eur Respir J 2014;44:1428-46.

20 Bestall JC, Paul EA, Garrod R, et al. Usefulness of the Medical Research Counci (MRC) dyspnoea scale as a measure of disability in patients with chronic obstructive pulmonary disease. Thorax 1999;54:581-6.

21 Jones PW, Harding G, Berry P, et al. Development and first validation of the COPD Assessment Test. EurRespirJ 2009:34:648-54.

22 Rubin BK, Ramirez O, Ohar JA. lodinated glycerol has no effect on pulmonary function, symptom score, or sputum properties in patients with stable chronic bronchitis. Chest 1996;109:348-52.

23 Comstock GW, Tockman MS, Helsing KJ, et al. Standardized respiratory questionnaires: comparison of the old with the new. Am Rev Respir Dis 1979:119:45-53.

24 Putcha N, Drummond MB, Connett JE, et al. Chronic productive cough is associated with death in smokers with early COPD. Copd 2014;11:451-8.

25 Smith BM, Hoffman EA, Rabinowitz D, et al. Comparison of spatially matched airways reveals thinner airway walls in COPD. The Multi-Ethnic Study of Atherosclerosis (MESA) COPD Study and the Subpopulations and Intermediate Outcomes in COPD Study (SPIROMICS). Thorax 2014;69:987-96.

26 Matsui EC, Hansel NN, Aloe C, et al. Indoor pollutant exposures modify the effect of airborne endotoxin on asthma in urban children. Am J Respir Crit Care Med 2013:188:1210-15.

27 Selvin S. Statistical analysis of epidemiologic data. New York: Oxford University Press, 1996.

28 Paulin LM, Diette GB, Blanc PD, et al. Occupational exposures are associated with worse morbidity in patients with chronic obstructive pulmonary disease. Am J Respir Crit Care Med 2015;191:557-65.

29 Centers for Disease Control and Prevention (CDC).Vital signs: nonsmokers' exposure to secondhand smoke—United States, 1999-2008. MMWR Morb Mortal Wkly Rep 2010;59:1141-6 
30 Mair G, Maclay J, Miller JJ, et al. Airway dimensions in COPD: Relationships with clinical variables. Respir Med 2010;104:1683-90.

31 Grydeland TB, Dirksen A, Coxson HO, et al. Quantitative computed tomography measures of emphysema and airway wall thickness are related to respiratory symptoms. Am J Respir Crit Care Med 2010;181:353-9.

32 Kratzer A, Salys J, Nold-Petry C, et al. Role of IL-18 in second-hand smoke-induced emphysema. Am J Respir Cell Mol Biol 2013;48:725-32.

33 Beatty AL, Haight TJ, Redberg RF. Associations between respiratory illnesses and secondhand smoke exposure in flight attendants: a cross-sectional analysis of the Flight Attendant Medical Research Institute Survey. Environ Health 2011;10:81
34 IARC Working Group on the Evaluation of Carcinogenic Risks to Humans. Tobacco smoke and involuntary smoking. IARC Monogr Eval Carcinog Risks Hum 2004;83:1-1438.

35 Lu KD, Breysse PN, Diette GB, et al. Being overweight increases susceptibility to indoor pollutants among urban children with asthma. J Allergy Clin Immunol 2013;131:1017-23, 23.e1-3.

36 Mancuso P. Obesity and lung inflammation. J Appl Physiol 2010;108:722-8.

37 Chalkiadaki A, Guarente L. High-Fat Diet Triggers Inflammation-Induced Cleavage of SIRT1 in Adipose Tissue To Promote Metabolic Dysfunction. Cell Metabolism 2012;16:180-8. 